\title{
Lymph Node Metastases in the Neck from Unknown Primary Sites
}

\author{
K. Al-Saleh ${ }^{a}$ A. Ali ${ }^{a}$ A.M. Jaffer ${ }^{b}$ T. Farghaley ${ }^{b}$ M.A. Abdulla ${ }^{c}$ \\ aKuwait Cancer Control Center, bENT Department, Al-Sabah Hospital, and \\ 'Department of Pathology, Faculty of Medicine, Kuwait University, Kuwait
}

\author{
Key Words \\ Unknown primary $\cdot$ Cervical lymph node . \\ Metastases
}

\begin{abstract}
Objective: To evaluate the experience of the Kuwait Cancer Control Center in the diagnosis and management of patients with cervical lymph node metastasis from an unknown primary site. Methods: We have undertaken a retrospective study of 24 patients for the years 1979-1994. All cases were pathologically confirmed; a primary tumor was not detected in any of these cases despite extensive diagnostic procedures. There were 24 patients, 9 Kuwaitis and 15 non-Kuwaitis, 20 males and 4 females (5:1). Their ages ranged from 10 to 83 years with a median of 55.5 years. Results: Twenty patients presented with a neck mass. The supraclavicular lymph node was the site in 9 cases; 9 had multinodal metastases, 3 in the upper third of the neck, 2 at the submental-submaxillary level and 1 in the middle third. The local stage of nodal involvement was $6 N_{1}, 8 N_{2}$ and $9 N_{3}$. The pathological diagnosis was squamous cell
\end{abstract}

\begin{tabular}{ll}
\hline KARGER & ( ) 2000 S. Karger AG, Basel \\
1011-7571/00/0091-0059\$17.50/0 \\
$\begin{array}{l}\text { Fax +4161306 1234 } \\
\begin{array}{l}\text { E-Mail karger@karger.ch } \\
\text { www.karger.com }\end{array}\end{array}$ & $\begin{array}{l}\text { Accessible online at: } \\
\text { www.karger.com/journals/mpp }\end{array}$
\end{tabular}

carcinoma in 14 cases, adenocarcinoma in 6 cases, 1 undifferentiated case and unknown in 2 cases. Sixteen cases were graded as poorly differentiated. Radiotherapy was used for 9 patients, 4 were treated with chemotherapy, 2 were treated with surgery, 2 were treated with surgery followed by radiotherapy and 2 with chemotherapy and radiotherapy. The median survival was 6 months for the whole group. Conclusion: We concluded that, in patients with metastatic carcinoma to the cervical lymph nodes from an unknown primary, supraclavicular localization and male gender were high risk factors. The prognosis in these cases was disastrous because of late diagnosis, and therapy was only palliative.

Copyright $(2000$ S. Karger AG, Basel

\section{Introduction}

Patients with cancer of an unknown primary site represent $5-10 \%$ of all head and neck cancer patients [1]. The incidence of a neoplasm as a cause of cervical adenopathy increases with age and should be suspected in any adult with this complaint [2]. More than 
$60 \%$ of the neck masses in patients older than 40 years are caused by malignant tumors [3], and $85 \%$ of them are from primary tumors in the head and neck area [4].

The definition of unknown primary tumor site varies; however, in this report we consider patients to have an unknown primary tumor site if no tumor is detected after an extensive search. The workup should consist initially of a thorough review of the patient's past and present history, family history and occupational history, and a complete physical examination. Radiological studies should be used including the chest radiograph which is helpful in screening for lung involvement. A thyroid scan or ultrasound may also be indicated if a thyroid nodule is present. Computed tomography (CT) is frequently helpful in determining whether other enlarged lymph nodes are present and where they are located. Fineneedle aspiration (FNA) with or without CT or ultrasound guidance is an excellent diagnostic method [5]. Magnetic resonance imaging has been used to improve the detection of occult lymph nodes [6].

We intend in this study, which is the first in Kuwait, to evaluate and assess the problem

Table 1. Nationality and sex distribution

\begin{tabular}{lclc}
\hline & Males & Females & Total \\
\hline Kuwaiti & 7 & 2 & 9 \\
Non-Kuwaiti & 13 & 2 & 15 \\
\hline Total & 20 & 4 & 24 \\
\hline
\end{tabular}

of lymph node metastases in the neck with no known primary tumor.

\section{Materials and Methods}

This study is a retrospective analysis of all patients with cervical metastases from an unknown primary site treated at the Kuwait Cancer Control Center (KCCC) between 1979 and 1994. The patients' records were reviewed using the following criteria for coding the data: (1) no primary site could be found, (2) all cases were pathologically confirmed and (3) a neck mass was the first presentation. The patient's age, sex, nationality, past history of tobacco smoking or alcohol drinking, presenting symptoms and location of the tumor were obtained. Staging was done according to the Tumor Node Metastases System (TNM), of the International Union against Cancer. Classification and grading, treatment modalities, follow-up and survival were also obtained. All patients had a complete physical examination, including examination under anesthesia with direct biopsies of the nasopharynx, tongue base and pyriform sinuses when indicated.

\section{Results}

In the period between 1979 and 1994, a total of 24 patients were registered at the Kuwait Cancer Registry as having cervical lymph node metastases with unknown primary. All results are depicted in tables 1-6. In none of the patients could a primary tumor be detected. They were 9 Kuwaitis and 15 nonKuwaitis; 4 of them were females and 20 were males. A very high male-to-female ratio was noted (table 1). Their ages ranged between 10 and 83 years with a median of 55.5 years (ta-

Table 2. Age and sex distributions

\begin{tabular}{lllllllll}
\hline & \multicolumn{2}{l}{ Years } & & & & & & \\
\cline { 2 - 8 } & $10-20$ & $20-30$ & $30-40$ & $40-50$ & $50-60$ & $60-70$ & $70-80$ & $>80$ \\
\hline Males & 1 & 2 & 4 & 4 & 2 & 4 & 2 & 1 \\
Females & & & & & 1 & 1 & 2 & \\
\hline
\end{tabular}


ble 2). The presenting symptom was a neck mass in 20 patients $(83.3 \%)$, pain in the neck in 2 patients $(8.3 \%)$, cough in 1 case $(4.2 \%)$ and nasal discharge in 1 case $(4.2 \%$; table 3$)$. The site of the mass was ascertained in our cases as follows: 9 multinodal metastases, 9 in the supraclavicular region, 3 in the upper third of the neck (level II), 2 in the submental/ submaxillary area (level I) and 1 in the middle third of the neck (level III; table 4).

Table 3. Presenting symptoms

\begin{tabular}{lcc}
\hline & Number & Percent \\
\hline Neck mass & 20 & 83.3 \\
Neck pain & 2 & 8.3 \\
Cough & 1 & 4.2 \\
Other (nasal discharge) & 1 & 4.2 \\
\hline Total & 24 & 100 \\
\hline
\end{tabular}

Table 4. Site of the tumor

\begin{tabular}{lcc}
\hline & Number & Percent \\
\hline Level I & 2 & 8.3 \\
Level II & 3 & 12.5 \\
Level III & 1 & 4.2 \\
Supraclavicular region & 9 & 37.5 \\
Multinodal & 9 & 37.5 \\
\hline Total & 24 & 100
\end{tabular}

Table 5. Size of the gland

\begin{tabular}{lcc}
\hline Size & Number & Percent \\
\hline $\mathrm{N}_{1}$ & 6 & 25 \\
$\mathrm{~N}_{2}$ & 8 & 33.3 \\
$\mathrm{~N}_{3}$ & 9 & 37.5 \\
Unknown & 1 & 4.2 \\
\hline Total & 24 & 100 \\
\hline
\end{tabular}

Lymph Node Metastases in the Neck from Unknown Primary Sites
Based on TNM classifiction, 6 cases $(25 \%)$ were categorized as $\mathrm{N}_{1}$ (less than $3 \mathrm{~cm}$ ), 8 cases $(33 \%)$ as $\mathrm{N}_{2}$ (between 3 and $6 \mathrm{~cm}$ ) and 9 cases $(37.5 \%)$ as $\mathrm{N}_{3}$ (more than $6 \mathrm{~cm}$; table 5 ). The histopathological diagnosis and grading of each lymph node biopsy were reviewed and were found as being squamous cell carcinoma (SCC) in 14 patients (58.3\%); adenocarcinoma was found in 6 cases (25\%), 1 case of lymphoepithelial carcinoma and 1 case of undifferentiated carcinoma. No pathological report was available in 2 cases. Fourteen patients from our group were tobacco users; 13 of them were heavy smokers ( $\geq 3$ packs/day). Only 1 patient was a smoker and alcohol abuser.

\section{Discussion}

Patients with cervical lymph node metastases from an unknown primary tumor present a diagnostic and therapeutic dilemma. They comprise $3-6 \%$ of patients with cervical adenopathy in Kuwait. Any neck mass

Table 6. Probable site of the primary tumor according to the location of the cervical metastases

\begin{tabular}{ll}
\hline $\begin{array}{l}\text { Location of } \\
\text { nodes }\end{array}$ & Primary tumor \\
\hline Submental & $\begin{array}{l}\text { floor of the mouth, lips and } \\
\text { anterior tongue } \\
\text { retromolar trigone and glosso- } \\
\text { palatine pillar } \\
\text { oral cavity, base of the tongue, } \\
\text { tonsil, nasopharynx and larynx } \\
\text { oral cavity, oropharynx, base of } \\
\text { the tongue and larynx } \\
\text { thyroid, larynx, hypopharynx and } \\
\text { nasopharynx }\end{array}$ \\
Midjugular & $\begin{array}{l}\text { Lung (40\%), thyroid (20\%), } \\
\text { gastrointestinal (12\%) and genito- } \\
\text { urinary }(8 \%)\end{array}$ \\
Supraclaviculariar jugular & nasopharynx \\
\hline
\end{tabular}

Med Principles Pract 2000;9:59-66 


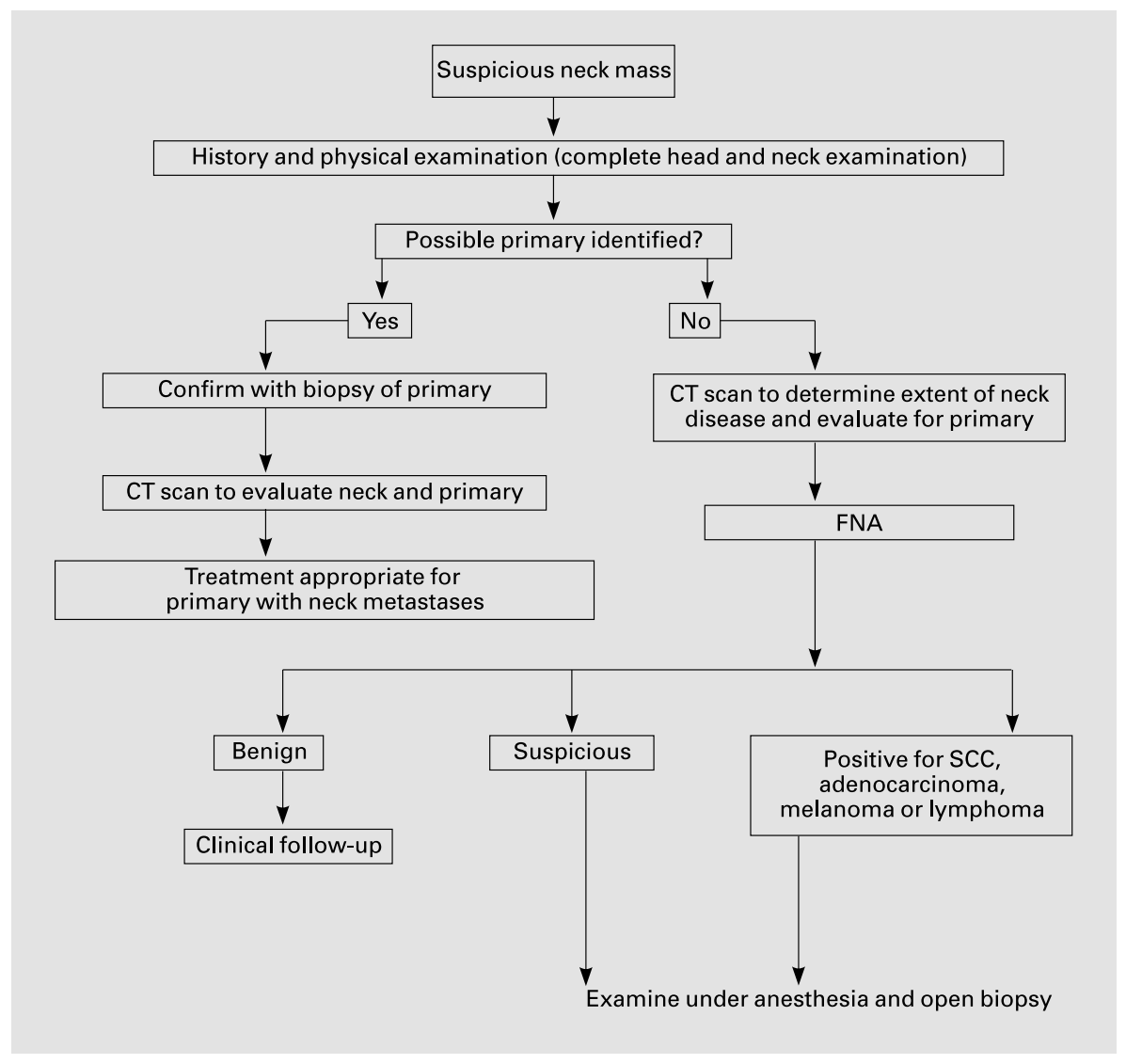

Fig. 1. Flowchart for workup of a neck node. Modified from Myers and Suen [6].

suspected of being malignant should be approached in a rational and organized manner (fig. 1), beginning with a pertinent history and complete physical examination. Factors increasing the likelihood of malignancy include: (1) age over 40 years; (2) excessive tobacco use; (3) excessive alcohol use; (4) a nontender enlarging mass; (5) obstructive symptoms of the airway; (6) hoarseness of voice over a 3week duration; (7) persistent throat pain for more than 3 weeks; (8) nonhealing ulceration; (9) previous radiation exposure, and (10) a history of cancer of the head and neck [6].

In our group the patients were predominantly males who were frequent smokers. The strength of association between cancer of the upper aerodigestive tract and tobacco abuse has been confirmed. This relationship was described over 35 years ago and has been well understood and documented for the last 25 years. The mechanism of carcinogenesis for tobacco is yet to be precisely determined; however, direct contact seems to be an important factor [7].

The prognostic factors that are felt to be important determinants in the survival of a patient with cervical node metastasis of unknown origin are: (1) position of the cervical node, (2) clinical stage of the lymph node, (3) histological type of the metastatic neo- 
plasm and (4) degree of differentiation. The site of lymphadenopathy was found as an important guide to investigations aimed at identifying the primary tumor site. Based on the metastatic pattern of head and neck cancers with known primary tumor site the most common primary tumor site for neck nodes in different areas can be predicted (table 6) [8]. Supraclavicular adenopathy most commonly indicates disease of the lung or gastrointestinal tract. These patients have a poorer prognosis than those with head and neck primaries. For this reason a palliative treatment approach in these patients might be more appropriate. In our study there were 9 cases of supraclavicular metastasis with an average survival rate of 3 months, compared to the remaining cases with an average survival of 8.5 months.

Careful staging of the disease is very important because the therapeutic approach varies depending on the dimension and distribution of the tumor. Although the prognosis of patients with $\mathrm{N}_{1}$ cervical nodes is relatively good, very poor therapeutic results and survival have been reported for $\mathrm{N}_{3}$ patients. Nevertheless, different studies proved the lack of correlation between histopathology and survival [1]; the prognosis is more dependent on clinical staging [9]. Histopathology of the supraclavicular node presentations are more likely to signify a more distant primary site and more widely spread dissemination. Needle biopsy can be employed to obtain FNA for cytology or core histopathology. The FNA technique has an accuracy rate of over $90 \%$ [6]. The value of FNA of neck lymph nodes deserves reemphasis. When performed during the initial patient visit, it can differentiate between benign lymphadenitis, lymphoma and metastatic carcinoma (fig. 2). Open biopsy is rarely used today because the FNA biopsy has proven to be accurate [10]. SCC to the neck usually arises from the head and neck area [11]. A possible explanation of the high incidence of poorly differen- tiated SCC ( $50 \%$ of all cases) is an occult nasopharyngeal origin (table 7). Most authors consider adenocarcinoma unfavorable with a high incidence in the supraclavicular nodes. The probabilities of pulmonary, breast or gastrointestinal origins are much higher and highly associated with a poor prognosis $[11,12]$.

Optimal treatment of the neck in cases of an unknown primary is controversial, but basically it involves surgery [3], radiotherapy [14] or both in several combinations depending on the situation [3]. It is necessary to adapt the therapy to the condition of the patient, the characteristics of the tumor and the treatment modalities available $[9,12,15]$. With metastatic SCC in the neck node, there are several options, depending upon whether the node was biopsied by needle or was excised. If the node is still present, in $\mathrm{N}_{1}$ stage, and there are no other nodes palpable, the treating physician may either do a neck dissection with postoperative radiation therapy to the neck and all of the upper aerodigestive tract areas or give radiation therapy only. With $\mathrm{N}_{2}$ or $\mathrm{N}_{3}$ neck nodes, the treatment of choice is a neck dissection followed by radiotherapy. If the node is fixed, then radiotherapy alone or in combination with chemotherapy is usually given first with the hope of making the neck operable. In the situation in which the node was excised and found to be a metastatic SCC, the recommendation is slightly different. Should the node be of $\mathrm{N}_{1}$ size, radiotherapy alone to the neck and the upper aerodigestive tract is probably adequate. For $\mathrm{N}_{2}$ and $\mathrm{N}_{3}$ nodes, neck dissection followed by radiotherapy is a proper approach [6]. If the diagnosis is lymphoma or lymphoepithelioma, no further surgery is indicated because radiation or chemotherapy, or both, would be the treatment of choice. With a diagnosis of adenocarcinoma, the treatment will depend on the possible primary site and the location of the positive node. In our collec- 


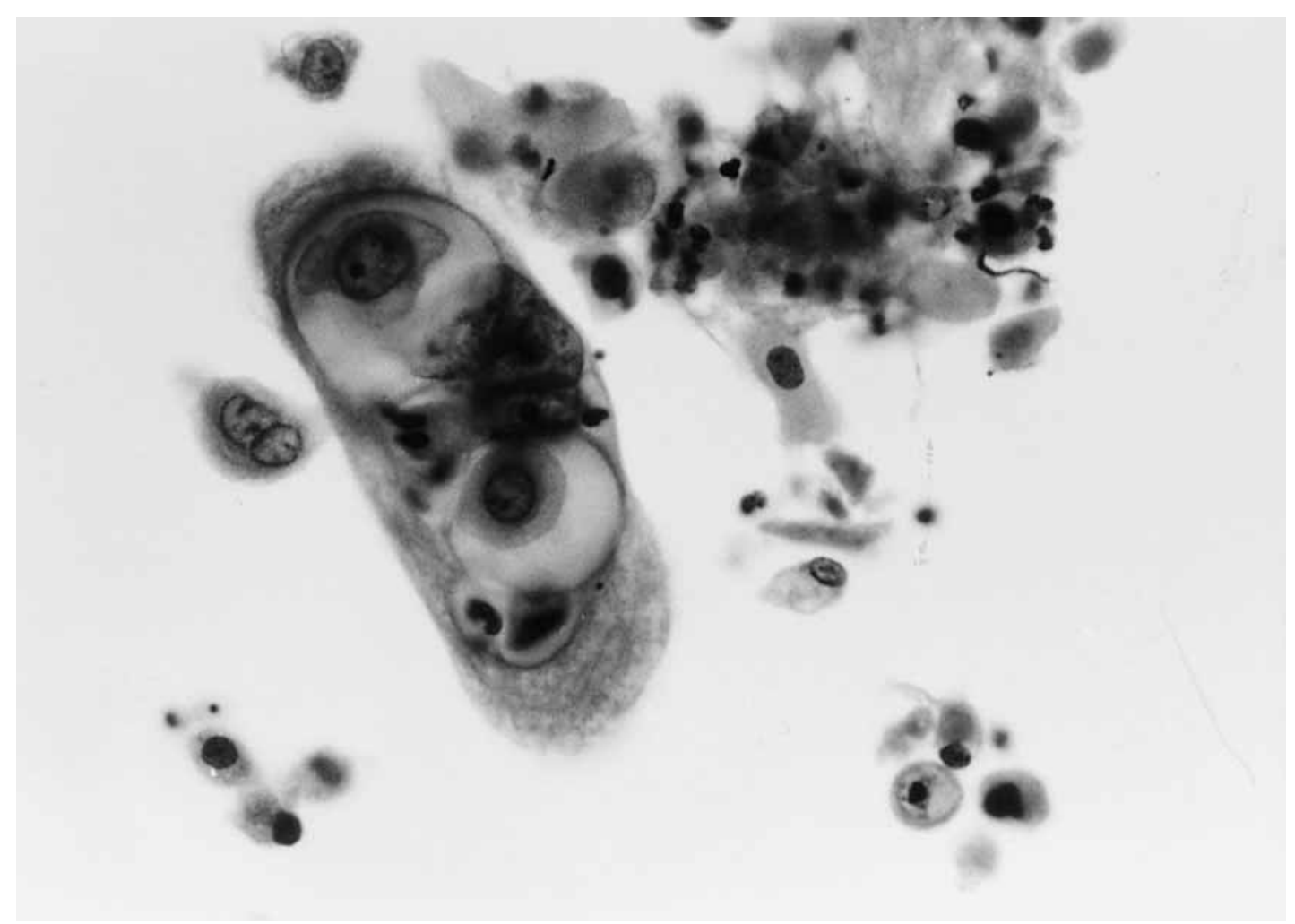

Fig. 2. a FNA of metastatic poorly differentiated SCC from an upper cervical lymph node. Pap stain. $\times 40$.

tion, 9 patients were treated with radiotherapy and 4 were treated with chemotherapy alone. Two patients were treated surgically and 2 were treated with combined surgery and radiotherapy. Two cases were treated with chemotherapy, followed by radiotherapy.

In the past, carcinoma metastatic to cervical nodes from an unknown primary was practically considered a hopeless situation with patient survival measured in months [16]. The results of our study and other similar studies must be interpreted with caution due to the relative infrequency of these cases, the long time span of the studies and small patient numbers which make it unlikely that prospective information will become available (table 8) [23]. As
Table 7. Histopathological grading

\begin{tabular}{lrc}
\hline Histopathology & Number & Percent \\
\hline SCC & 14 & 58.3 \\
$\quad$ Well differentiated & 1 & \\
$\quad$ Moderately differentiated & 1 & \\
$\quad$ Poorly differentiated & 12 & \\
Adenocarcinoma & 6 & 25.0 \\
$\quad$ Moderately differentiated & 2 & \\
$\quad$ Poorly differentiated & 4 & \\
Lymphoepithelial carcinoma & 1 & 4.2 \\
Undifferentiated carcinoma & 1 & 4.2 \\
Unknown & 2 & 8.3 \\
\hline Total & 24 & 100 \\
\hline
\end{tabular}

Al-Saleh/Ali/Jaffer/Farghaley/Abdulla 


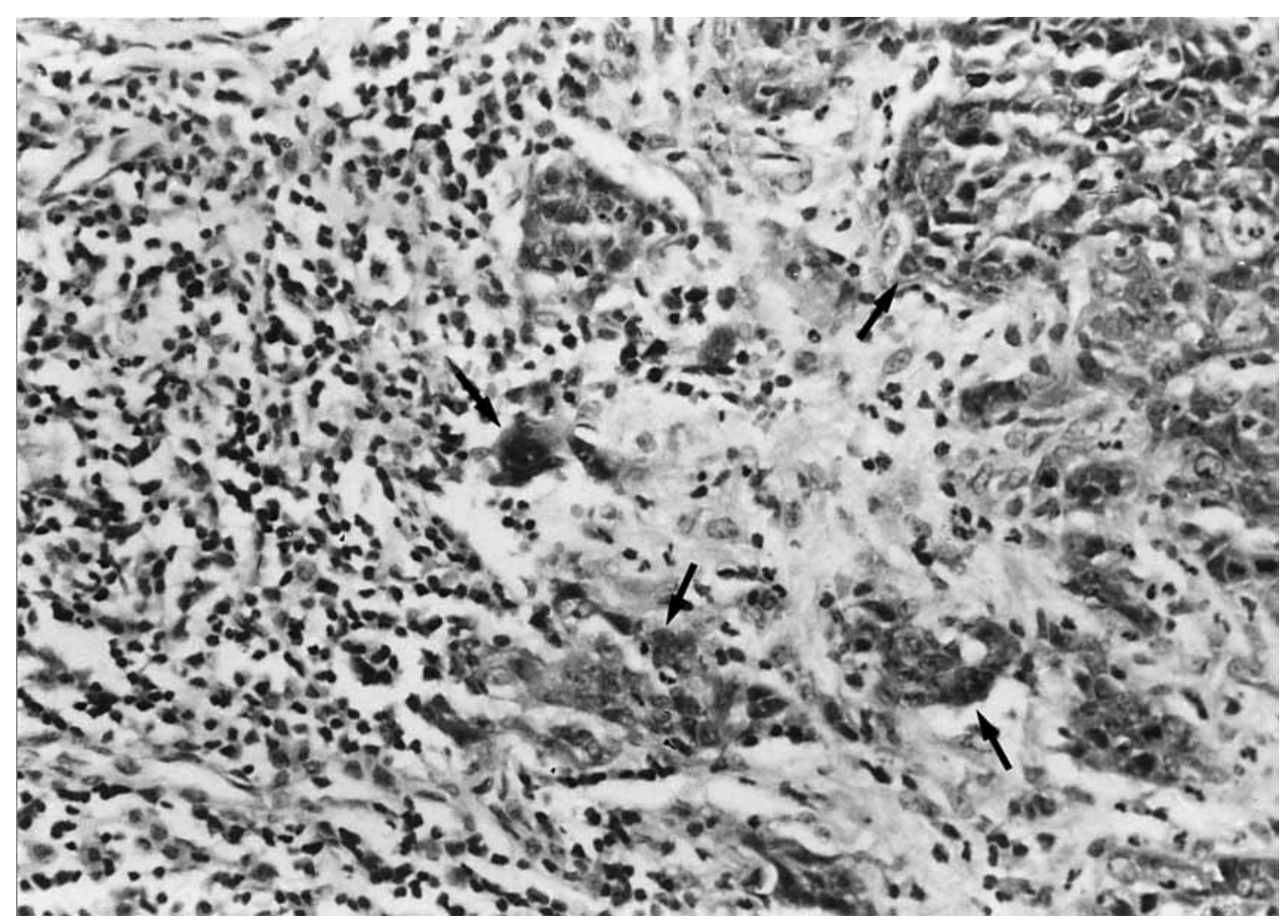

Fig. 2. b Section from the lymph node with metastatic SCC of the same case. Malignant squamous cells (arrows). HE stain. $\times 20$.

Table 8. Unknown primary series published from 1980 to the present time

\begin{tabular}{|c|c|c|c|c|c|c|c|c|c|c|c|c|}
\hline \multirow{2}{*}{\multicolumn{2}{|c|}{ Senior author }} & \multirow{2}{*}{$\begin{array}{l}\text { Year of } \\
\text { publi- } \\
\text { cation }\end{array}$} & \multirow{2}{*}{$\begin{array}{l}\text { Age of } \\
\text { patients } \\
\text { followed } \\
\text { years }\end{array}$} & \multirow[t]{2}{*}{ Patients } & \multirow{2}{*}{$\begin{array}{l}\text { Median } \\
\text { age } \\
\text { years }\end{array}$} & \multirow{2}{*}{$\begin{array}{l}\mathrm{M} / \mathrm{F} \\
\text { ratio }\end{array}$} & \multicolumn{3}{|c|}{ Treatment, \% } & \multirow[t]{2}{*}{ SCC } & \multicolumn{2}{|c|}{ Histology } \\
\hline & & & & & & & $\mathrm{Cx}$ & XRT & Sx & & undiff. & adeno. \\
\hline 1 & Leipzig [17] & 1981 & $69-77$ & 48 & 51 & 2: 1 & & & & 32 & & 16 \\
\hline 2 & Silverman [18] & 1983 & $64-79$ & 83 & $>40$ & $58: 25$ & & 80 & 25 & 58 & 24 & \\
\hline 3 & Spiro [14] & 1983 & $65-76$ & 132 & $56-61$ & $76: 45$ & & 39 & 78 & $60 \%$ & $10 \%$ & $22 \%$ \\
\hline 4 & Bataini [13] & 1987 & $60-80$ & 138 & 57.5 & $117: 21$ & & 65 & 35 & $100 \%$ & & \\
\hline 5 & de Braud [19] & 1989 & $76-87$ & 41 & 58 & $28: 13$ & 16 & 16 & 9 & 85 & $7 \%$ & \\
\hline 6 & Harper [20] & 1990 & $64-86$ & 69 & 61.4 & $58: 11$ & & 93 & 26 & $100 \%$ & & \\
\hline 7 & Wang [21] & 1990 & $53-88$ & 157 & 60.5 & 4: 1 & & 62 & 64 & $100 \%$ & & \\
\hline 8 & Maulard [22] & 1992 & $72-86$ & 113 & 59 & $96: 17$ & & 100 & 100 & $100 \%$ & & \\
\hline 9 & Coster [3] & 1992 & $65-87$ & 24 & 63 & 3: 1 & & & 100 & $100 \%$ & & \\
\hline 10 & Myers [6] & 1996 & $78-91$ & 48 & 59 & $34: 14$ & 3 & 27 & 37 & 42 & 3 & 3 \\
\hline
\end{tabular}

$\mathrm{Cx}=$ Chemotherapy; $\mathrm{Sx}=$ surgery $\mathrm{XRT}=$ radiotherapy treatment. 
a group, our patients exhibited poor survival, with a median of 6 months of living. Patient survival seems to be greatly influenced by the presence of extracapsular spread [24].

Marksman's study [25] of 245 patients with adenocarcinoma of unknown primary origin at the Johns Hopkins Hospital from 1965 to 1979 showed a median survival of 13 months. A median survival of 4.5 months was noted for 87 patients with adenocarcino- ma of undetermined origin who were treated by Stewart et al. [26].

The majority of studies on this subject in the literature are retrospective. The interpretation of information is difficult because of the presence of the inherent biases of retrospective reviews. The findings of our study should be further investigated using randomized prospective, cooperative studies with other centers.

\section{References}

1 McCunnif AJ, Raben M: Metastatic carcinoma of the neck from an unknown primary. Int J Radiat Oncol Biol Phys 1986;12:1849-1852.

2 Coker DD, Casterline PF, Chambers RG, Jaques DA: Metastases to lymph node of the head and neck from unknown primary site. Am J Surg 1977;134:517-522.

3 Coster JR, Foote RL, Olsen KD, Jack SM, Schaid DJ, DiSanto LW: Cervical nodal metastases of squamous cell carcinoma of unknown origin: Indications for withholding radiation therapy. Int J Radiat Oncol Biol Phys 1992;23:743-749.

4 Damion J, Hybels RL: The neck mass, inflammatory and neoplastic causes. Postgrad Med 1987;81:97107.

5 Chen VSM, Qizilbash A, Young JEM: Guides to Clinical Aspiration Biopsy: Head and Neck. New York, Igaku-Shoin, 1996, p 257.

6 Myers E, Suen J: Cancer of the Head and Neck, ed 3. Philadelphia, Saunders Co, 1996, p 466.

7 Keller AZ, Terris M: The association of alcohol and tobacco with cancer of the mouth and pharynx. Am J Public Health 1965;55:15781586.

8 De Braud F, Al Sarraf M: Chemotherapy as part of the treatment of patients with squamous cell carcinoma (SCC) of unknown primary metastatic to the neck. Proc Am Soc Clin Oncol 1988;7:156.

9 Fitzpatrick PJ, Kotalik JF: Cervical metastases from an unknown primary tumor. Radiology 1974;110:659663.
10 Young JEM, Archibald ST, Shierk J: Needle aspiration cytologic biopsy in head and neck masses. Am J Surg 1981;142:484.

11 Shaw HJ: Metastatic carcinoma in cervical lymph nodes with occult primary tumor: Diagnosis and treatment. J Laryngol Otol 1970;84:249265.

12 Jesse RH, Peres CA, Fletcher GH: Cervical lymph node metastases: Unknown primary cancer. Cancer 1973;31:854-859.

13 Bataini JP, Rodriguez J, Jaulerry C, Brugere J, Ghossein NA: Treatment of metastatic neck nodes secondary to an occult epidermoid carcinom of the head and neck. Laryngoscope 1987;97:1080-1084.

14 Spiro RH, DeRose G, Strong EW: Cervical node metastasis of occult origin. Am J Surg 1983;146:441446.

15 Jose B, Bosch A: Metastasis to neck from unknown primary tumor. Acta Radiol Oncol 1979;18:161.

16 Feldman PS: Pathologic and cytologic diagnosis of a lymph node with a neck mass. Head Neck Cancer 1985;1:281-283.

17 Leipzig B, Winter ML, Hokanson JA: Cervical nodal metastases of unknown origin. Laryngoscope 1981; 91:593-598.

18 Silverman CL, Marks J, Lee F, Ogura JH: Treatment of epidermoid and undifferentiated carcinomas from occult primaries presenting in cervical lymph nodes. Laryngoscope 1983;93:645-648.

19 DeBraud F, Heilbrun LK, Ahmed Skar W, Ensley JF, Kish JA, Tapazoglou E, Al-Sarraf M: Metastatic squamous cell carcinoma of an unknown primary localized to the neck. Advantages of an aggressive treatment. Cancer 1989;64:510-515.

20 Harper CS, Mendenhall WM, Parsons JT, Stringer SP, Cassisi NJ, Million RR: Cancer in neck nodes with unknown primary site: Role of mucosal radiotherapy. Head and Neck 1990;112:463-469.

21 Wang RC, Goepfert H, Barber AE, Wolf P: Unknown primary squamous cell carcinoma metastatic to the neck. Archives of Otolaryngology. Head and Neck Surgery 1990; 116:1388-1393.

22 Maulard C, Housset M, Brunel P, Huart J, Ucla L, Rozec C, Delanian $\mathrm{S}$, Baillet F: Post-operative radiation therapy for cervical lymph node metastases from an occult squamous cell carcinoma. Laryngoscope 1992; 102:884-890.

23 Talmi Y, Wolf G, Hazuka M, Krause C: Unknown primary of the head and neck. J Laryngol Otol 1996;110:353-356.

24 Som P: Detection of metastases in cervical lymph nodes: CT and MR criteria and differential diagnosis. AJR Am J Roentgenol 1992;158: 961-969.

25 Markman M: Metastatic adenocarcinoma of unknown primary site: Analysis of 245 patients seen at the Johns Hopkins Hospital from 1965 to 1979 . Med Pediatr Oncol 1982; 10:569-574.

26 Stewart JF, Tattersall MH, Woods RL, Fox RM: Unknown primary adenocarcinoma: Incidence of overinvestigation and natural history. $\mathrm{Br}$ Med J 1979;i:530-533. 